\title{
Autophagy manipulation as a strategy for efficient anticancer therapies: possible consequences
}

\author{
Mara Cirone ${ }^{1,2^{*}}$, Maria Saveria Gilardini Montani ${ }^{1,2}$, Marisa Granato ${ }^{1,2}$, Alessia Garufi, ${ }^{3,4}$, Alberto Faggioni ${ }^{1,2}$ and \\ Gabriella D'Orazi ${ }^{3,4^{*}}$ (D)
}

\begin{abstract}
Autophagy is a catabolic process whose activation may help cancer cells to adapt to cellular stress although, in some instances, it can induce cell death. Autophagy stimulation or inhibition has been considered an opportunity to treat cancer, especially in combination with anticancer therapies, although autophagy manipulation may be viewed as controversial. Thus, whether to induce or to inhibit autophagy may be the best option in the different cancer patients is still matter of debate. Her we will recapitulate the possible advantages or disadvantages of manipulating autophagy in cancer, not only with the aim to obtain cancer cell death and disable oncogenes, but also to evaluate its interplay with the immune response which is fundamental for the success of anticancer therapies.
\end{abstract}

Keywords: Autophagy, Cancer, Immunogenic cell death (ICD), Endoplasmic reticulum (ER stress), Unfolded protein response (UPR), Chloroquine (CQ), Hydroxichloroquine (HCQ), p53, HSF1, NRF2

\section{Background}

Macroautophagy, hereafter referred as autophagy, is a bulk degradative process up-regulated under stressful conditions, playing a central role in cellular homeostasis [1]. Autophagy usually helps cancer cells to cope with the shortage of nutrients and with the hypoxic conditions in which they are forced to survive. The modulation of autophagy may play dual roles in tumor suppression and promotion [2, 3]. Its induction is generally considered a valid option in cancer prevention [4], particularly because through a selective form of autophagy, that is the mitophagy, cells ride out of damaged mitochondria, the main producers of reactive oxygen species (ROS) that cause DNA mutations [5]. Autophagy modulators have been used as new anticancer strategy $[3,6]$, although how to manipulate autophagy to improve the treatment of established cancers is still not clear. Recently, a role of

\footnotetext{
*Correspondence: mara.cirone@uniroma1.it; gdorazi@unich.it 'Department of Experimental Medicine, "Sapienza" University of Rome, Rome, Italy

${ }^{3}$ Department of Medical Science, University 'G. D'Annunzio', 66013 Chieti, Italy

Full list of author information is available at the end of the article
}

autophagy in the regulation the function of the cells present in the tumor microenvironment such as cancerassociated fibroblasts and immune cells has been highlighted, making the issue of autophagy manipulation even more challenging [7, 8]. Even if many reviews have been published in the last years about autophagy and cancer, here, we will try to recapitulate the multifaceted role of autophagy in cancer therapy and how its manipulation may impact immune response that plays an essential role in tumor regression.

\section{Interplay between autophagy and immune system in anticancer therapies}

The inhibition of autophagy has been pursued as a possible avenue to treat cancer, considering that autophagy represents a mechanism of adaption to stress especially when exacerbated by chemotherapies [9]. Indeed, excluding the rare and debated cases in which chemotherapies may induce an autophagic cell death [10], autophagy is triggered along with apoptosis as a prosurvival mechanism, as also evidenced by our studies [11-16]. Based on this knowledge, in vivo studies have started to employ autophagy inhibitors, such as

(c) The Author(s). 2019 Open Access This article is distributed under the terms of the Creative Commons Attribution 4.0 International License (http://creativecommons.org/licenses/by/4.0/), which permits unrestricted use, distribution, and 
inhibitors of the lysosomal protease and anti-malaric drugs, Chloroquine (CQ) or Hydroxichloroquine (HCQ), to treat cancer, more often in combination with chemotherapies able to induce autophagy [17-19]. Such combinations, mainly used to treat cancer in xenograft mouse models, have registered some successes in controlling tumor growth and prolonging host survival [20-22]. However, in order to avoid tumor rejection, immune deficient mice have been used for these experiments, thus cutting out the possibility to explore the direct and indirect role of autophagy inhibitors on the cells of the immune system [8]. Moving forward, the impact of autophagy inhibition in combination with chemotherapy has been explored also in immune competent mice. Surprisingly, these studies demonstrate that the depletion of essential autophagyrelevant gene products such as autophagy related (ATG) 5 or beclin 1 (BECN1) [1-3], although increase the cancer cytotoxic effect of therapy in vitro and in vivo in immune deficient mice, reduce the efficacy of radiotherapy or chemotherapy in immune competent mice [23] (Fig. 1a). These findings were somehow surprising because it raised many questions about the likely key role of the immune response for efficient anticancer therapies in the course of autophagy manipulation. In the mean time, several molecules exposed on the cancer cell surface or released by dying cancer cells upon chemotherapies, were discovered to elicit an immunogenic dell death (ICD) able to activate the immune system [24, 25]. In this regard, our studies identified Calreticulin and Heat Shock Protein (HSP) 90 as the Damage Associated Molecular Patterns (DAMPs) exposed on the surface of dying lymphoma cells treated by Bortezomib, and the CD91 as the receptor molecule involved in their recognition by dendritic cells (DCs) $[26,27]$. DCs are powerful antigen-presenting cells (APCs) that play a pivotal role initiating a specific immune response and in the eradication of apoptotic cancer cells by mediating the cross-presentation of tumor antigens to the cytotoxic $\mathrm{T}$ cells, therefore, their function is fundamental for immune response activation [28]. Further investigations have highlighted that autophagy strongly contributes to the immunogenicity of cell death, promoting the release of adenosine triphosphate (ATP), a DAMP

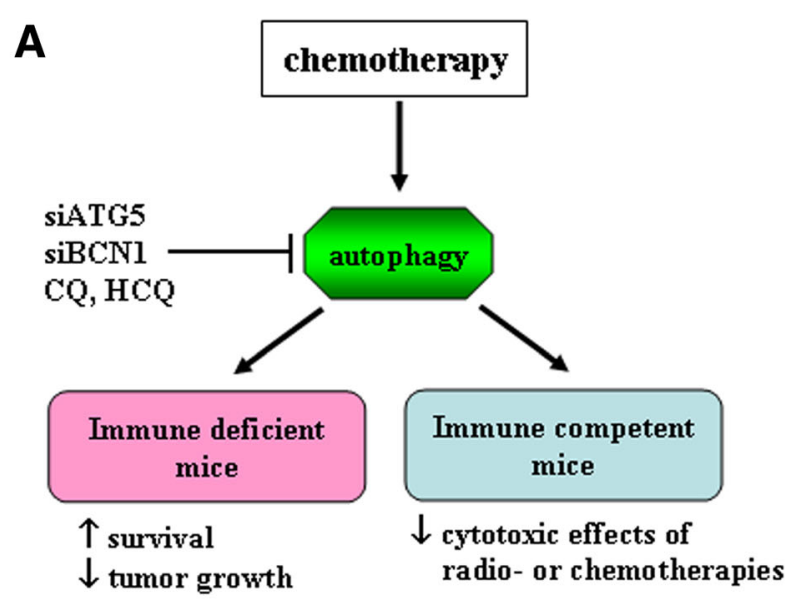

B
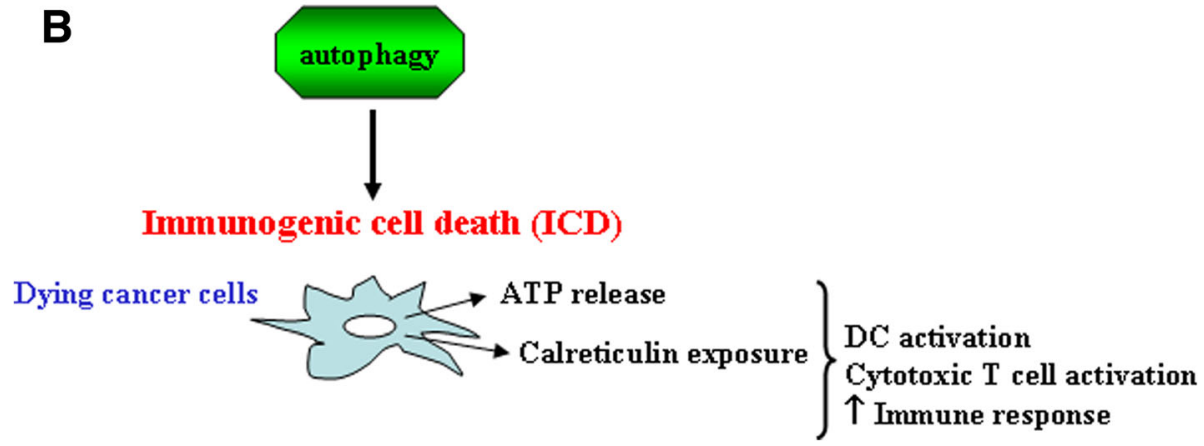

Fig. 1 a Schematic representation of blockade of chemotherapies-induced autophagy and the relative outcome in tumor xenografts of immune deficient mice or immune competent mice models. b Schematic representation of immunogenic cell death (ICD) induced by autophagy. Dying cancer cells because chemotherapies activate autophagy that allows ATP release and calreticulin exposure that favor the activation of the immune response 
that plays a key role in immune cell activation $[23,29,30]$ (Fig. 1b). These findings could explain why the combination of chemotherapy with autophagy inhibitors did not give the expected result in tumor models in immune competent mice, as it now clear enough that the contribution of the immune response is essential for a successful antitumor therapy.

Despite the unclear role of autophagy inhibition in improving the outcome of chemotherapies, clinical trials have started to use CQ or $\mathrm{HCQ}$, mainly in combination with chemotherapies, to treat cancer patients $[9,31,32]$. The results so far obtained have been quite disappointing and the treatment failure may be explained also by the reduction of autophagy-induced ATP release, and by the fact that these anti-malaric drugs inhibit lysosomal acidification, thus may affect many other important cellular processes other than autophagy [33]. Moreover, when systemically administrated, CQ or HCQ may have several side effects [34] and act on immune cells suppressing their functions, i.e. stimulating the $\mathrm{T}$ regulatory cells (Treg) [35], altering class II antigen presentation or cross-presentation by DCs [36] or even impairing DC formation, all mechanisms inducing suppression of the immune response [37]. Interestingly, the reduction of autophagy in monocytes represents a strategy through which the human oncogenic gammaherpesviruses Epstein-Barr virus (EBV) and Kaposi's sarcoma-associated herpesvirus (KSHV) alter monocyte differentiation into DCs, to escape from immune recognition, as also demonstrated by our studies [38-40]. In line with the evidences indicating that autophagy is required for an effective immune response and for the activation of immune system in the course of anticancer chemotherapies, we have found that autophagy inhibitor CQ abrogates the cytotoxic effect of curcumin against breast cancer in immune competent mice while increases it in immune deficient mice [40]. These findings point out, once again, that autophagy inhibition reduces the success of anticancer therapy in the presence of a functional immune system. Moreover, this study evidenced that CQ counteracts the curcumin downregulation of Hypoxia Inducing Factor (HIF)-1, the main effector of cellular response to hypoxia involved in cancer progression and chemoresistance [41], and that sustained HIF-1 activation correlates with higher infiltrate of immune suppressive Treg cells in the tumor bed of curcumin plus CQ-treated mice [40]. In agreement, previous studies have shown that HIF-1 could be degraded through the lysosomal route [42, 43], suggesting that autophagy inhibition by CQ may interfere with HIF-1 degradation promoted by curcumin and sustain its oncogenic function for tumor progression.

\section{Autophagy and oncogenes degradation}

Here we come to another important and probably under-estimated role of autophagy in cancer, namely its capacity to degrade molecules involved in tumor survival, progression or chemoresistance, such as oncogenes or mutated oncosuppressor genes. At this purpose, our and other's laboratories have shown that some mutant (mut) p53 proteins, that acquire pro-oncogenic functions (gain-of-function, GOF) [44], may undergo degradation through autophagy [45-48] or through chaperonemediated autophagy (CMA) [49], both inhibited by the use of CQ and HCQ. While wild-type p53 has been reported to induce autophagy, mutp53 has been reported to reduce autophagy, especially when it is localized in the cytoplasm as a self-protective mechanism $[16,50]$, or through stimulation of the mammalian target of rapamycin (mTOR) pathway, sustaining tumor progression [51, 52]. Interestingly, mutp53 may activate HIF-1 [53] and it could be speculated that the inhibition of autophagy by mutp53 might promote HIF-1 activation, given that HIF-1 is degraded through the lysosomal route $[42,43]$. The best described mechanism of mutp53 GOF is its ability to interact with transcription factors, remodelling the cancer cell transcriptome and proteome in such a way to support cancer cell survival, tumor progression, invasion, metastasis and chemoresistance [54]. Thus, other than interacting with HIF-1, mutp53 may interact and contribute to the activation of Heat Shock Factor 1 (HSF1) [55], a transcription factor that maintains cellular homeostasis by stress-mediated induction of HSP and coordinates cellular processes critical for malignancy such as metastasis and inhibition of apoptosis [56, 57]. Interestingly HSF1, activated in response to proteotoxic stress and basally activated in cancer cells [55], has been shown to be degraded through autophagy [58]. HSF1 can engage a cross-talk with nuclear factor erytroid 2 like (NRF2/NFE2L2) [59], the main transcription factor regulating the antioxidant response [60]. HSF1 and NRF2 regulate autophagy [60] and both promote the transcription of sequestosome 1/p62 (SQSTM1/p62) [59], a protein that is indeed up-regulated in stressful conditions. SQSTM1/p62 is mainly degraded through autophagy and thus is considered a marker to evaluate the completeness of the autophagic flux, as it accumulates when autophagy is inhibited [1]. SQSTM1/p62 may control a variety of other cellular processes involved in cell death or survival decision $[61,62]$. Importantly, SQSTM1/ p62 may stabilize NRF2, by degradation of NRF2 negative regulator kelch like ECH associated protein (Keap)1, thus linking autophagy to the anti-oxidant response [63] (Fig. 2) . NRF2 is another transcription factor with which mutp53 may interact, promoting the transcription of pro-survival antioxidant enzymes [54] and this interplay with oncogenes further sustain tumor progression [64]. Included in the list of oncogenic transcription factors interconnected with mutp53 [65] and regulated by autophagy there is also c-myc, thus our studies showed that autophagy 


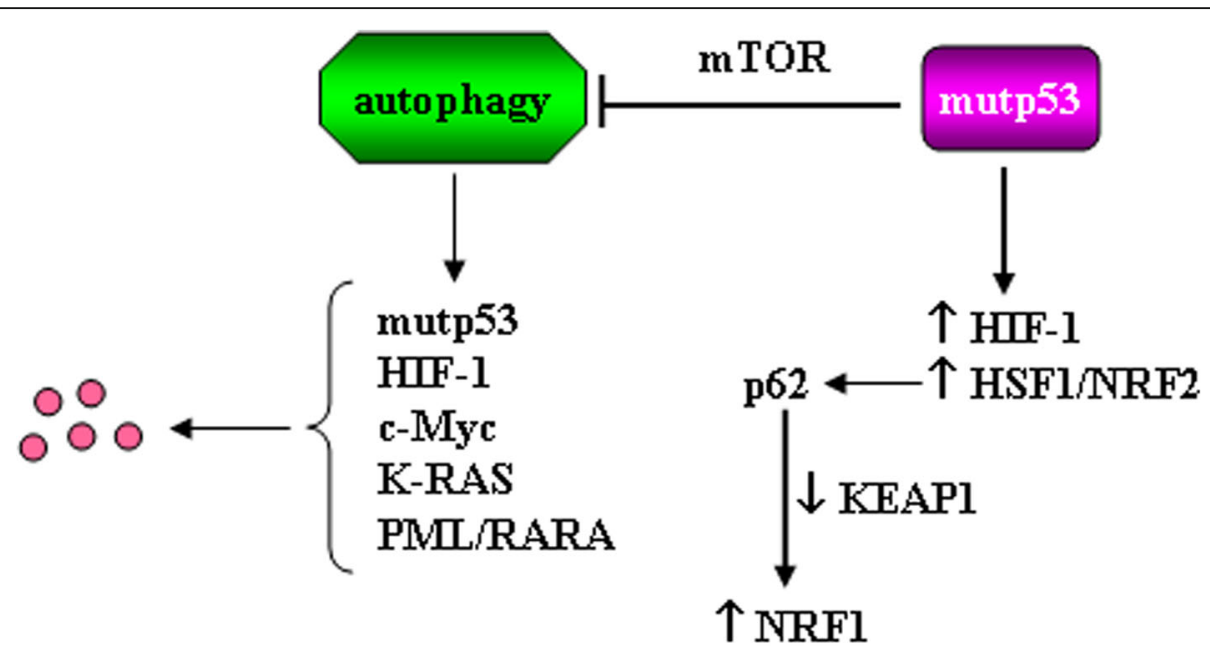

\section{Figure 2}

Fig. 2 Schematic representation of the effect of autophagy on oncogenes degradation. The role of mutp53 in blocking autophagy and sustaining oncogenes activation is also shown

contributes to its degradation in Burkitt's lymphoma cells treated with quercetin [66]. Furthermore, other oncogenic proteins such as K-RAS [67] and PML/RARA [68] can be degraded through autophagy and interact with mutp53 $[69,70]$ (Fig. 2). It is somehow intriguing that the expression of mutp53 and of many other oncogenic proteins interconnected with it may be regulated by autophagy and/or may regulate autophagy. The number of these oncogenic proteins is increasing, suggesting that other molecules involved in cancer development, survival and progression could come out to be regulated by autophagy. Considering that the oncogenic pathways may activate each other and that such cross-talk, besides cancer cells, may influence the function of immune cells, many other important effects of autophagy manipulation could be discovered. For example, it has been recently shown that $\mathrm{PI} 3 \mathrm{~K} / \mathrm{AKT} / \mathrm{mTOR}$ pathway, the master regulator of autophagy, often activated in cancer cells, may be involved in the up-regulation of the immune check-point inhibitor PD-L1 [71] whose expression on the tumor cells, by interacting with PD-1 on T cell surface, induces $\mathrm{T}$ cell exhaustion [72, 73]. It will be important to further explore the interplay between autophagy and PD-L1 expression, for example in cancer cells harboring mutp53, whose expression inhibits autophagy and activates mTOR.

Interplay between autophagy, endoplasmic reticulum (ER) stress and unfolded protein response (UPR)

Last but not least, it must be considered the interplay between autophagy, Endoplasmic Reticulum (ER) stress and Unfolded protein response (UPR) in the regulation of cancer cell survival [74]. Many reviews have been recently published elucidating the role of ER stress, UPR and autophagy in cancer [75-78]. The ER stress is induced by several cellular stresses that activates UPR to reduce the amount of misfolded proteins through ubiquitinproteasome-dependent ERAD (ER-associated degeneration) and autophagy activation that restores ER homeostasis [75, 76, 78]. Under prolonged and irreversible ER stress, cells undergo apoptosis (Fig. 3) [75, 76, 78]. The UPR is indeed a transcriptional program that induces adaptation, survival, transformation, angiogenesis and resistance to cell death through three main sensors localized at the ER membrane: the inositol-requiring enzyme $1 \alpha$ (IRE1 $\alpha$ ), PKR-like ER kinase (PERK) and the activating transcription factor 6 (ATF6) [79]. IRE1 $\alpha$ transautophosphorylation induces cleavage of XB1 leading to expression of the transcription factor XBP1s that regulates the expression of genes related with folding, entry of proteins to the ER, ER-associated degradation (ERAD) and biogenesis of ER and Golgi; PERK activation favours the phosphorylation of eIF $2 \alpha$ (eukaryotic translation initiation factor $2 \alpha$ ) and the selective translation of ATF4 (activating transcription factor 4), regulating the expression genes involved in folding, oxidative stress and amino acid metabolism; ATF6 translocates to the nucleus to induce the transcription of genes involved in ER homeostasis, and ERAD components (Fig. 3) [75-79]. ER stress is known to promote autophagy, and although the interplay between them remains still to be fully elucidated, the activation of UPR arms EIF2 $\alpha$ and IRE1 have been reported to trigger autophagy $[76,80]$. On the other hand, the inhibition of autophagy may exacerbate ER stress [80], altering the activation of UPR arms, leading for example to the up- 


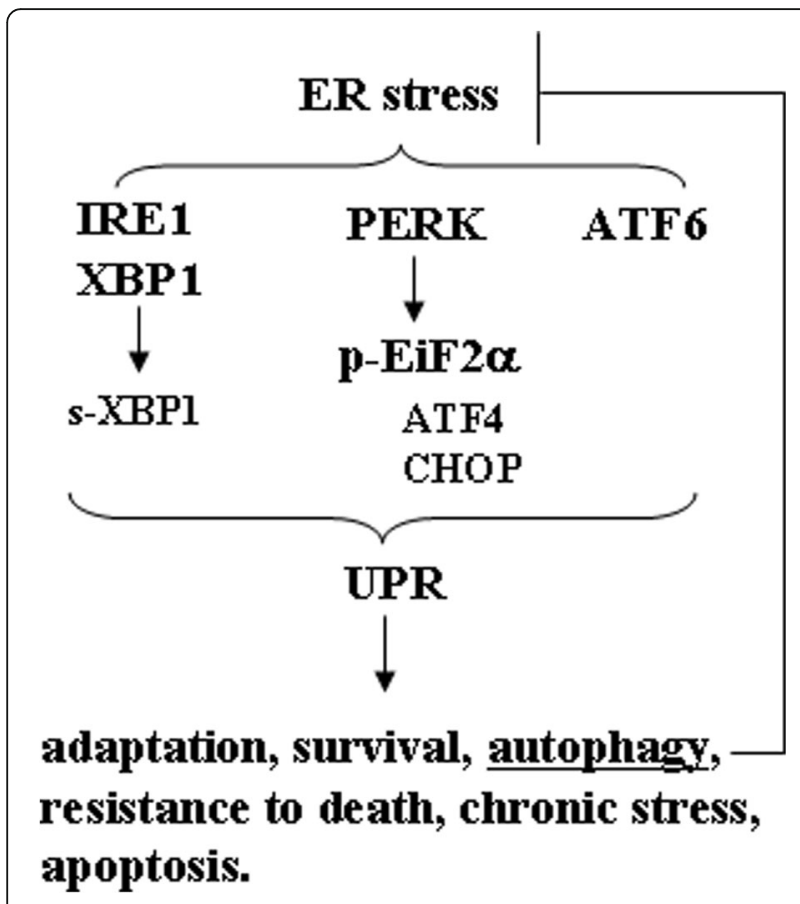

Fig. 3 Molecular mechanisms of ER stress unfolded protein response (UPR) pathways. The three main sensors of UPR, localized at the ER membrane, and activated are inositol-requiring enzyme 1a (IRE1a), PKR-like ER kinase (PERK), and activating transcription factor 6 (ATF6). The autophagy induction alleviates the ER stress

regulation of the pro-apoptotic molecule C/EBP homologous protein (CHOP). Of note, $\mathrm{CHOP}$ can activate Cyclooxigenase (COX)-2 that in turn may promote the release of Prostaglandin (PG) E2, a DAMP that induces immune suppression $[81,82]$. Moreover, ER stress in cancer cells promotes the release of factors such as ROS that may transfer ER stress from tumor cells to the immune cells, such as DCs, in the tumor environment. This event may activate the endoribonucleasic activity of IRE1 $\alpha$ in $\mathrm{DC}$, inducing the splicing of $\mathrm{X}$-box binding protein (XBP1s). The formation of XBP1s may in turn promote an abnormal accumulation of peroxidized lipids, strongly impairing the immune function of DCs [83]. XBP1s' activation and the up-regulation of $\mathrm{CHOP}$ have been also observed in myeloid suppressive DCs (MDSCs) present in the tumor environment [84]. Interestingly, it has been reported that ER stress can be transferred from cancer cells also to macrophages, promoting their polarization into M2 phenotype [85], tumor-associated macrophages that support instead of fighting tumor [86].

\section{Conclusions}

Based on the findings reported by the majority of studies in this field, it seems that autophagy induction rather than autophagy inhibition could be exploited to improve the outcome of cancer treatment, at least in immune competent hosts. Therefore, nutraceuticals, exercise, calory restriction or calory restriction mimetics (such as metformin), all able to induce autophagy, are being considered as a possible alternative avenue to treat cancer in combination with chemotherapies [87, 88]. In addition, just to make this complicated field more complicated, it is emerging that inhibiting autophagy specifically in cancer cells may enhances the abscopal response to radiation therapy, that is, the ability of localized radiation to trigger systemic antitumor effects $[89,90]$. thus suggesting that selective autophagy inhibition in cancer cells and systemic induction of autophagy could be combined to improve the outcome of anti-cancer therapy. Considering the role of autophagy in regulating the expression of oncogenes and modulating the function of the cells of the tumor environment such as fibroblasts and immune cells, more questions than answers have been raised by this review. Therefore, more investigations are needed to further clarify the possible consequences of autophagy manipulation in cancer therapy.

\section{Abbreviations}

APCs: Antigen-presenting cells; ATG5: Autophagy related 5; ATP: Adenosine triphosphate; BECN1: Beclin 1; CHOP: C/EBP homologous protein; COX2: Cyclooxigenase-2; CQ: Chlororoquine; DAMPs: Damage Associated Molecular Patterns; DCs: dendritic cells; EBV: Epstein-Barr virus;

EIF2a: Eukaryotic translation initiation factor 2a; ER: Endoplasmic Reticulum; HCQ: Hydroxichloroquine; HIF-1: Hypoxia Inducible Factor-1; HSF1: Heat Shock Factor 1; HSP90: Heat shock protein 90; ICD: Immunogenic dell death; Keap1: kelch like ECH associated protein 1; KSHV: Kaposi's sarcoma-associated herpesvirus; MDSCs: myeloid suppressive DCs; mTOR: Mammalian target of rapamycin; NRF2: Nuclear factor erytroid 2 like; PGE2: Prostaglandin E2; ROS: Reactive oxygen species; SQSTM1: Sequestosome 1; UPR: Unfolded protein response; XBP1: X-box binding protein 1

\section{Acknowledgements}

We thank all the people in the lab for critical discussion.

\section{Authors' contributions}

Conception and design: MC, GD; Writing: MC, GD; revision of the manuscript: MSGM, MG, AG, AF. All authors read and approved the final manuscript.

Funding

The research in M.C.'s lab within the realm of this manuscript is funded by Istituto Pasteur Italia Fondazione Cenci Bolognetti and by Fondi Ateneo; in G.D.' lab is funded by AIRC and by Fondi Ateneo.

Availability of data and materials

All data analysed in this study are included in this published article.

Ethics approval and consent to participate

Not applicable.

Consent for publication

Not applicable.

Competing interests

The authors declare that they have no competing interests.

\section{Author details}

'Department of Experimental Medicine, "Sapienza" University of Rome, Rome, Italy. ${ }^{2}$ Laboratory affiliated to Istituto Pasteur Italia-Fondazione Cenci Bolognetti, Rome, Italy. ${ }^{3}$ Department of Medical Science, University 'G. D'Annunzio', 66013 Chieti, Italy. ${ }^{4}$ Department of Research, IRCCS Regina Elena National Cancer Institute, 00144 Rome, Italy. 
Received: 30 May 2019 Accepted: 10 June 2019

Published online: 14 June 2019

\section{References}

1. Klionsky DJ, Abdelmohsen K, Abe A, Abedin MJ, Abeliovich H, Acevedo Arozena A, et al. Guidelines for the use and interpretation of assays for monitoring autophagy (3rd edition). Autophagy. 2016;12:1-222.

2. Yun CW, Lee SH. The roles of autophagy in Cancer. Int J Mol Sci. 2018; 19:3466.

3. Udristioiu A, Nica-Badea D. Autophagy dysfunctions associated with cancer cells and their therapeutic implications. Biomed Pharmacother. 2019;115: 108892.

4. Galluzzi L, Bravo-San Pedro JM, Kroemer G. Defective autophagy initiates malignant transformation. Mol Cell. 2016;62:473-4.

5. Poillet-Perez L, Despouy G, Delage-Mourroux R, Boyer-Guittaut M. Interplay between ROS and autophagy in cancer cells, from tumor initiation to cancer therapy. Redox Biol. 2015:4:184-92.

6. Jiang J, Li H, Qaed E, Zhang J, Song Y, Wu R, et al. Salinomycin, as an autophagy modulator-- a new avenue to anticancer: a review. J Exp Clin Cancer Res. 2018;37:26.

7. Yan Y, Chen X, Wang X, Zhao Z, Hu W, Zeng S, et al. The effects and the mechanisms of autophagy on the cancer-associated fibroblasts in cancer. J Exp Clin Cancer Res. 2019;38:171.

8. Jiang GM, Tan Y, Wang H, Peng L, Chen HT, Meng XJ, et al. The relationship between autophagy and the immune system and its applications for tumor immunotherapy. Mol Cancer. 2019;18:17.

9. Marinkovic M, Sprung M, Buljubasic M, Novak I. Autophagy modulation in cancer: current knowledge on action and therapy. Oxidative Med Cell Longev. 2018;2018:8023821.

10. Fulda S. Autophagy in cancer therapy. Front Oncol. 2017;7:128.

11. Granato M, Santarelli R, Lotti LV, Di Renzo L, Gonnella R, Garufi A, et al. JNK and macroautophagy activation by bortezomib has a pro-survival effect in primary effusion lymphoma cells. PLoS One. 2013;8:e75965.

12. Granato M, Chiozzi B, Filardi MR, Lotti LV, Di Renzo L, Faggioni A, et al. Tyrosine kinase inhibitor tyrphostin AG490 triggers both apoptosis and autophagy by reducing HSF1 and Mcl-1 in PEL cells. Cancer Lett. 2015;366:191-7.

13. Granato M, Rizzello C, Gilardini Montani MS, Cuomo L, Vitillo M, Santarelli R, et al. Quercetin induces apoptosis and autophagy in primary effusion lymphoma cells by inhibiting PI3K/AKT/mTOR and STAT3 signaling pathways. J Nutr Biochem. 2017;41:124-36.

14. Masui A, Hamada M, Kameyama H, Wakabayashi K, Takasu A, Imai T, et al. Autophagy as a survival mechanism for squamous cell carcinoma cells in endonuclease G-mediated apoptosis. PLoS One. 2016;11:e0162786.

15. Granato M, Gilardini Montani MS, Santarelli R, D'Orazi G, Faggioni A, Cirone M. Apigenin, by activating p53 and inhibiting STAT3, modulates the balance between pro-apoptotic and pro-survival pathways to induce PEL cell death. J Exp Clin Cancer Res. 2017;36:167.

16. Garufi A, Pistritto G, Baldari S, Toietta G, Cirone M, D'Orazi G. p53-dependent PUMA to DRAM antagonistic interplay as a key molecular switch in cell-fate decision in normal/high glucose conditions. J Exp Clin Cancer Res. 2017;36:126

17. Li J, Hou N, Faried A, Tsutsumi S, Kuwano H. Inhibition of autophagy augments 5-fluorouracil chemotherapy in human colon cancer in vitro and in vivo model. Eur J Cancer. 2010;46:1900-9.

18. Levy JMM, Towers CG, Thorburn A. Targeting autophagy in cancer. Nat Rev Cancer. 2017;17:528-42.

19. Verbaanderd $C$, Maes $H$, Schaaf MB, Sukhatme VP, Pantziarka P, Sukhatme $V$, et al. Repurposing drugs in oncology (ReDO)-chloroquine and hydroxychloroquine as anti-cancer agents. Ecancermedicalscience. 2017;11:781.

20. Jia L, Wang J, Wu T, Wu J, Ling J, Cheng B. In vitro and in vivo antitumor effects of chloroquine on oral squamous cell carcinoma. Mol MedRep. 2017;16:5779-86

21. Zhao XG, Sun RJ, Yang XY, Liu DY, Lei DP, Jin T, et al. Chloroquineenhanced efficacy of cisplatin in the treatment of hypopharyngeal carcinoma in xenograft mice. PLoS One. 2015;10:e0126147.

22. Chou HL, Lin YH, Liu W, Wu CY, Li RN, Huang HW, et al. Combination therapy of chloroquine and C(2)-ceramide enhances cytotoxicity in lung cancer H460 and H1299 cells. Cancers (Basel). 2019;11:370.
23. Michaud M, Martins I, Sukkurwala AQ, Adjemian S, Ma Y, Pellegatti P, et al. Autophagy-dependent anticancer immune responses induced by chemotherapeutic agents in mice. Science. 2011;334:1573-7.

24. Cirone M, Di Renzo L, Lotti LV, Conte V, Trivedi P, Santarelli R, et al. Activation of dendritic cells by tumor cell death. Oncoimmunol. 2012;1:1218-9.

25. Kepp O, Senovilla L, Vitale I, Vacchelli E, Adjemian S, Agostinis P, et al. Consensus guidelines for the detection of immunogenic cell death. Oncoimmunol. 2014;3:e955691.

26. Cirone M, Di Renzo L, Lotti LV, Conte V, Trivedi P, Santarelli R, et al. Primary effusion lymphoma cell death induced by bortezomib and AG 490 activates dendritic cells through CD91. PLoS One. 2012;7:e31732.

27. Garufi A, Pistritto G, Ceci C, Di Renzo L, Santarelli R, Faggioni A, et al. Targeting COX-2/PGE(2) pathway in HIPK2 knockdown cancer cells: impact on dendritic cell maturation. PLoS One. 2012;7:e48342.

28. Mellman I. Dendritic cells: master regulators of the immune response. Cancer Immunol Res. 2013:1:145-9.

29. Martins I, Michaud M, Sukkurwala AQ, Adjemian S, Ma Y, Shen S, et al. Premortem autophagy determines the immunogenicity of chemotherapyinduced cancer cell death. Autophagy. 2012;8:413-5.

30. Wang Y, Martins I, Ma Y, Kepp O, Galluzzi L, Kroemer G. Autophagydependent ATP release from dying cells via lysosomal exocytosis. Autophagy. 2013;9:1624-5.

31. Galluzzi L, Bravo-San Pedro JM, Demaria S, Formenti SC, Kroemer G. Activating autophagy to potentiate immunogenic chemotherapy and radiation therapy. Nat Rev Clin Oncol. 2017;14:247-58.

32. Chude Cl, Amaravadi RK. Targeting autophagy in cancer: update on clinical trials and novel inhibitors. Int J Mol Sci. 2017:18:E1279.

33. Kroemer G, Galluzzi L. Lysosome-targeting agents in cancer therapy. Oncotarget. 2017:8:112168-9.

34. Kimura T, Takabatake Y, Takahashi A, Isaka Y. Chloroquine in cancer therapy: a double-edged sword of autophagy. Cancer Res. 2013;73:3-7.

35. Thome R, Issayama LK, DiGangi R, Bombeiro AL, da Costa TA, Ferreira IT, et al. Dendritic cells treated with chloroquine modulate experimental autoimmune encephalomyelitis. Immunol Cell Biol. 2014;92:124-32.

36. Accapezzato D, Visco V, Francavilla V, Molette C, Donato T, Paroli M, et al. Chloroquine enhances human CD8+ T cell responses against soluble antigens in vivo. J Exp Med. 2005:202:817-28.

37. Zhang Y, Morgan MJ, Chen K, Choksi S, Liu ZG. Induction of autophagy is essential for monocyte-macrophage differentiation. Blood. 2012;119:2895-905.

38. Gilardini Montani MS, Santarelli R, Falcinelli L, Gonnella R, Granato M, Di Renzo L, et al. EBV up-regulates PD-L1 on the surface of primary monocytes by increasing ROS and activating TLR signaling and STAT3. J Leuk Biol. 2018:104:821-32.

39. Santarelli R, Granato M, Pentassuglia G, Lacconi V, Gilardini Montani MS, Gonnella $\mathrm{R}$, et al. KSHV reduces autophagy in THP-1 cells and in differentiating monocytes by decreasing CAST/calpastatin and ATG5 expression. Autophagy. 2016;12:2311-25.

40. Masuelli L, Granato M, Benvenuto M, Mattera R, Bernardini R, Mattei M, et al Chloroquine supplementation increases the cytotoxic effect of curcumin against Her2/neu overexpressing breast cancer cells in vitro and in vivo in nude mice while counteracts it in immune competent mice. Oncoimmunol. 2017;6:e1356151.

41. Soni S, Padwad YS. HIF-1 in cancer therapy: two decade long story of a transcription factor. Acta Oncol. 2017;56:503-15.

42. Hubbi ME, Hu H, Kshitiz GDM, Semenza GL. Sirtuin-7 inhibits the activity of hypoxia-inducible factors. J Biol Chem. 2013;288:20768-75.

43. DePavia A, Jonasch E, Liu XD. Autophagy degrades hypoxia inducible factors. Mol Cell Oncol. 2016:3:e1104428.

44. Schulz-Heddergott R, Moll UM. Gain-of-function (GOF) mutant p53 as actionable therapeutic target. Cancers (Basel). 2018;10:E188.

45. Garufi A, D'Orazi G. High glucose dephosphorylates serine 46 and inhibits p53 apoptotic activity. J Exp Clin Cancer Res. 2014:33:79.

46. Baldari S, Ubertini V, Garufi A, D'Orazi G, Bossi G. Targeting MKK3 as a novel anticancer strategy: molecular mechanisms and therapeutical implications. Cell Death Dis. 2015;6:e1621

47. Garufi A, D'Orazi V, Crispini A, D'Orazi G. Zn(II)-curc targets p53 in thyroid cancer cells. Int J Oncol. 2015;47:1241-8.

48. Garufi A Ubertini V, Mancini F, D'Orazi V Baldari S, Moretti F, et al. The beneficial effect of zinc(II) on low-dose chemotherapeutic sensitivity 
involves p53 activation in wild-type p53-carrying colorectal cancer cells. J Exp Clin Cancer Res. 2015;34:87.

49. Vakifahmetoglu-Norberg H, Kim M, Xia HG, Iwanicki MP, Ofengeim D, Coloff $\mathrm{JL}$, et al. Chaperone-mediated autophagy degrades mutant p53. Genes Dev. 2013;27:1718-30

50. Morselli E, Tasdemir E, Maiuri MC, Galluzzi L, Kepp O, Criollo A, et al. Mutant p53 protein localized in the cytoplasm inhibits autophagy. Cell Cycle. 2008;7:3056-61.

51. Cordani M, Oppici E, Dando I, Butturini E, Dalla Pozza E, Nadal-Serrano M, et al. Mutant p53 proteins counteract autophagic mechanism sensitizing cancer cells to mTOR inhibition. Mol Oncol. 2016;10:1008-29.

52. Dando I, Pacchiana R, Pozza ED, Cataldo I, Bruno S, Conti P, et al. UCP2 inhibition induces ROS/Akt/mTOR axis: role of GAPDH nuclear translocation in genipin/everolimus anticancer synergism. Free Radic Biol Med. 2017:113:176-89

53. Galluzzi L, Vitale I, Aaronson SA, Abrams JM, Adam D, Agostinis P, et al. Molecular mechanisms of cell death: recommendations of the nomenclature committee on cell death 2018. Cell Death Diff. 2018;25:486-541.

54. Mantovani F, Collavin L, Del Sal G. Mutant p53 as a guardian of the cancer cell. Cell Death Diff. 2019;26:199-212.

55. Li D, Yallowitz A, Ozog L, Marchenko N. A gain-of-function mutant p53HSF1 feed forward circuit governs adaptation of cancer cells to proteotoxic stress. Cell Death Dis. 2014;5:e1194.

56. Home T, Jensen RA, Rao R. Heat shock factor 1 in protein homeostasis and oncogenic signal integration. Cancer Res. 2015;75:907-12.

57. Gomez-Pastor R, Burchfiel ET, Thiele DJ. Regulation of heat shock transcription factors and their roles in physiology and disease. Nat Rev Mol Cell Biol. 2018;19:4-19.

58. Kim E, Sakata K, Liao FF. Bidirectional interplay of HSF1 degradation and UPR activation promotes tau hyperphosphorylation. PLoS Genet. 2017;13: e1006849.

59. Dayalan Naidu S, Kostov RV, Dinkova-Kostova AT. Transcription factors Hsfi and Nrf2 engage in crosstalk for cytoprotection. Trends Pharmacol Sci. 2015; 36:6-14.

60. Dayalan Naidu S, Dikovskaya D, Gaurilcikaite E, Knatko EV, Healy ZR, Mohan $\mathrm{H}$, et al. Transcription factors NRF2 and HSF1 have opposing functions in autophagy. Sci Rep. 2017;7:11023.

61. Mathew R, Karp CM, Beaudoin B, Vuong N, Chen G, Chen HY, et al. Autophagy suppresses tumorigenesis through elimination of p62. Cell. 2009:137:1062-75.

62. Moscat J, Diaz-Meco MT. p62 at the crossroads of autophagy, apoptosis, and cancer. Cell. 2009:137:1001-4.

63. Katsuragi Y, Ichimura Y, Komatsu M. p62/SQSTM1 functions as a signaling hub and an autophagy adaptor. FEBS J. 2015;282:4672-8.

64. D'Orazi G, Cirone M. Mutant p53 and cellular stress pathways: a criminal alliance that promotes cancer progression. Cancers (Basel). 2019;11:614.

65. Liao P, Zeng SX, Zhou X, Chen T, Zhou F, Cao B, et al. Mutant p53 gains its function via C-Myc activation upon CDK4 phosphorylation at serine 249 and consequent PIN1 binding. Mol Cell. 2017:68:1134-46.

66. Granato M, Rizzello C, Romeo MA, Yadav S, Santarelli R, D'Orazi G, et al. Concomitant reduction of c-Myc expression and PI3K/AKT/mTOR signaling by quercetin induces a strong cytotoxic effect against Burkitt's lymphoma. Int J Biochem Cell Biol. 2016:79:393-400.

67. Kohli L, Kaza N, Coric T, Byer SJ, Brossier NM, Klocke BJ, et al. 4Hydroxytamoxifen induces autophagic death through K-Ras degradation. Cancer Res. 2013;73:4395-405.

68. Isakson P, Bjoras M, Boe SO, Simonsen A. Autophagy contributes to therapyinduced degradation of the PML/RARA oncoprotein. Blood. 2010;116:2324-31

69. Bailey JM, Hendley AM, Lafaro KJ, Pruski MA, Jones NC, Alsina J, et al. p53 mutations cooperate with oncogenic Kras to promote adenocarcinoma from pancreatic ductal cells. Oncogene. 2016;35:4282-8.

70. Haupt S, Raghu D, Haupt Y. Mutant p53 drives Cancer by subverting multiple tumor suppression pathways. Front Oncol. 2016;6:12.

71. Lastwika KJ, Wilson W 3rd, Li QK, Norris J, Xu H, Ghazarian SR, et al. Contro of PD-L1 expression by oncogenic activation of the AKT-MTOR pathway in non-small cell lung cancer. Cancer Res. 2016;76:227-38.

72. Thommen DS, Koelzer VH, Herzig P, Roller A, Trefny M, Dimeloe S, et al. A transcriptionally and functionally distinct PD-1(+) CD8(+) T cell pool with predictive potential in non-small-cell lung cancer treated with PD-1 blockade. Nat Med. 2018;24:994-1004.
73. Wang X, Wu WKK, Gao J, Li Z, Dong B, Lin X, et al. Autophagy inhibition enhances PD-L1 expression in gastric cancer. J Exp Clin Cancer Res. 2019;38:140

74. Mahadevan NR, Zanetti M. Tumor stress inside out: cell-extrinsic effects of the unfolded protein response in tumor cells modulate the immunological landscape of the tumor microenvironment. J Immunol. 2011;187:4403-9.

75. Yadav RK, Chae SW, Kim HR, Chae HJ. Endoplasmic reticulum stress and cancer. J Cancer Prev. 2014;19:75-88.

76. Senft D, Ronai ZA. UPR, autophagy, and mitochondria crosstalk underlies the ER stress response. Trends Biochem Sci. 2015;40:141-8.

77. Chevet E, Hetz C, Samali A. Endoplasmic reticulum stress-activated cell reprogramming in oncogenesis. Cancer Discov. 2015;5:586-97.

78. Urra H, Dufey E, Avril T, Chevet E, Hetz C. Endoplasmic reticulum stress and the hallmarks of Cancer. Trends Cancer. 2016;2:252-62.

79. Avril T, Vauleon E, Chevet E. Endoplasmic reticulum stress signaling and chemotherapy resistance in solid cancers. Oncogenesis. 2017;6:e373.

80. Romeo MA, Masuelli L, Gaeta A, Nazzari C, Granato M, Gilardini Montani MS, et al. Impact of HHV-6A and HHV-6B lytic infection on autophagy and endoplasmic reticulum stress. J Gen Virol. 2019;100:89-98.

81. Hangai S, Ao T, Kimura Y, Matsuki K, Kawamura T, Negishi H, et al. PGE2 induced in and released by dying cells functions as an inhibitory DAMP. Proc Natl Acad Sci U S A. 2016:113:3844-9.

82. Roberts HR, Smartt HJ, Greenhough A, Moore AE, Williams AC, Paraskeva C. Colon tumour cells increase PGE(2) by regulating COX-2 and 15-PGDH to promote survival during the microenvironmental stress of glucose deprivation. Carcinogenesis. 2011:32:1741-7.

83. Cubillos-Ruiz JR, Silberman PC, Rutkowski MR, Chopra S, Perales-Puchalt A, Song $\mathrm{M}$, et al. ER stress sensor XBP1 controls anti-tumor immunity by disrupting dendritic cell homeostasis. Cell. 2015;161:1527-38.

84. Condamine T, Ramachandran I, Youn Jl, Gabrilovich DI. Regulation of tumor metastasis by myeloid-derived suppressor cells. Annual Rev Med. 2015;66:97-110.

85. Oh J, Riek AE, Weng S, Petty M, Kim D, Colonna M, et al. Endoplasmic reticulum stress controls M2 macrophage differentiation and foam cell formation. J Biol Chem. 2012;287:11629-41.

86. Zheng X, Turkowski K, Mora J, Brune B, Seeger W, Weigert A, et al. Redirecting tumor-associated macrophages to become tumoricidal effectors as a novel strategy for cancer therapy. Oncotarget. 2017;8:48436-52.

87. Pietrocola F, Pol J, Vacchelli E, Baracco EE, Levesque S, Castoldi F, et al. Autophagy induction for the treatment of cancer. Autophagy. 2016:12:1962-4.

88. Rybstein MD, Bravo-San Pedro JM, Kroemer G, Galluzzi L. The autophagic network and cancer. Nat Cell Biol. 2018;20:243-51.

89. Reynders K, Illidge T, Siva S, Chang JY, De Ruysscher D. The abscopal effect of local radiotherapy: using immunotherapy to make a rare event clinically relevant. Cancer Treat Rev. 2015:41:503-10.

90. Ko A, Kanehisa A, Martins I, Senovilla L, Chargari C, Dugue D, et al. Autophagy inhibition radiosensitizes in vitro, yet reduces radioresponses in vivo due to deficient immunogenic signalling. Cell Death Diff. 2014:21:92-9.

\section{Publisher's Note}

Springer Nature remains neutral with regard to jurisdictional claims in published maps and institutional affiliations.

Ready to submit your research? Choose BMC and benefit from

- fast, convenient online submission

- thorough peer review by experienced researchers in your field

- rapid publication on acceptance

- support for research data, including large and complex data types

- gold Open Access which fosters wider collaboration and increased citations

- maximum visibility for your research: over $100 \mathrm{M}$ website views per year

At BMC, research is always in progress.

Learn more biomedcentral.com/submissions 